\title{
Üriner Sistem Taş Hastalığı ve Ağrı Tedavisi: Yeni Ne Var?
}

\author{
Göksel Bayar ${ }^{1}$, Orhan Tanrıverdi²
}

${ }^{1}$ idil Devlet Hastanesi, Üroloji Kliniği, Şırnak

${ }^{2}$ Bahçeşehir Üniversitesi, Tıp Fakültesi, Üroloji Ana Bilim Dalı, Liv Hospital, İstanbul

\section{Üriner Sistem Taş Hastalığında Ağrının Fizyopatolojisi}

$\mathrm{U}$ luslararası Ağrı Çalışma Derneği (IASP), ağrı hissini "Vücudun herhangi bölgesinde hissedilen, organik bir nedene bağlı olan veya olmayan, kişinin geçmişteki deneyimleri ile ilgili, sensoryal, emosyonel, hoş olmayan bir deneyim" olarak tanımlamıştır. Ağrı her ne kadar rahatsız edici olsa da; vücudumuzu ters giden olaylar nedeniyle uyarması açısından hayati öneme sahiptir. Akut ağrı, bir anlamda, vücudun yardım alması için zorlanmasıdır ve bu sayede gelişebilecek hasarlar önlenebilir (1). Ancak olay büyüdüğünde veya sürekli hale geldiğinde ağrı kronik hale gelir.

Üriner sistemde olan bir taş iki farklı mekanizmayla ağrıya sebep olabilir. Birincisi taşın gerisinde olan distansiyona bağlı olarak oluşan, ikincisi de direkt mukozal irritasyon neticesinde ortaya çıkan ağrıdır. İkisinde de aynı sinir yolağı kullanılır ve bu nosiseptörlerle başlayan viseral sempatik yolaktır. Nosiseptörler multimodal olup termo, kemo ve mekanosensitiftirler. Ancak burada etkin olan mekanosen-

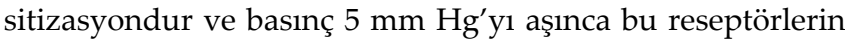
$\% 75$ 'i aktiflenir. Enfeksiyon ve direkt irritasyon gibi nedenlerle inflamasyon olduğunda hem sessiz mekanoreseptörler aktiflenir, hem de tüm reseptörlerin uyarılma eşiği düşser. $\mathrm{Bu}$ nedenle ağrı daha şiddetli ve daha uzun süre hissedilir. Ağrı T8-L2 dermatom sahasında yansıyan somatik ağrı olarak da hissedilebilir. Subkostal, iliohipogastrik, ilioinguinal ve genitofemoral sinirlerin duyusunu aldığı her yerde ağrı hissedilebilir ve bu sinirlerin innerve ettiği kaslarda kramplar görülebilir $(2,3)$.

Böbrek ağrısı 12. kosta altında ve sakroiliak kasın lateralinde "flank bölge" dediğimiz daha sinırl bir bölgede görülürken, üreter ağrısı kostovertebral açı bölgesinden erkekte skrotuma, kadında labium majusa kadar uzanan geniş bir alanda görülebilir. Taş üriner sistemi obstrükte ettikten sonra gerilen böbrek kapsülü ve üreterin muskularis tabakası ağriya sebep olur. Oluşan obstrüksiyonu aşmak için böbrek pelvis basıncını artırır ve üreter peristaltizmi de artar. Bu nedenle ağrılar kolik tarzdadır $(2,4)$. Ancak erken dönemde belirgin bir dilatasyon hastaların ancak \%18'inde tespit edilebilirken, hastaların \%11'inde dilatasyon olmaksızın ağrı gelişebilir. Dilatasyon olmadan oluşan ağrının sebebi ya hastanın ağrı ve kusmaya bağlı olarak dehidrate olması ya da; taşın direkt mukoza üzerine olan etkisinin ağriya neden olmasıdır (5).

\section{Renal Kolikle ilk Karşılaşma}

Renal kolikle başvuran bir hastada tanı konulduktan sonra ilk yapılması gereken üriner sistem enfeksiyonu ve/ veya progresyon gösteren post-renal böbrek yetmezliğini ekarte etmektir. Çünkü böyle bir durumda acil üriner dekompresyon gerekmektedir (6). Bunlar yapılırken ağrı da süratle giderilmelidir (7). Ağrıyı en kesin tedavi etmenin yolu tabi ki; taşın tedavi edilmesidir. Sarıca ve ark.'ları $5 \mathrm{~mm}$ veya daha büyük üreter taşı olan hastalara ilk renal kolik atağında acil üreteroskopi yapılmasının elektif şartlarda yapılmasıyla benzer başarı ve komplikasyon oranına sahip olduğunu bildirmişlerdir. Böylece hastaların daha az konforsuz dönem geçirdiklerini belirtmişlerdir (8). Benzer bir çalışmada da; taş boyutuna bakılmaksızın, acil veya elektif yapılan üreteroskopi karşılaştıııldığında benzer sonuçlar elde edilmiştir (9). Avrupa Üroloji Derneği (EAU) kılavuzunda, analjezik tedaviyle hastanın ağrısı giderilebiliyorsa ve taş boyutu $6 \mathrm{~mm}$ veya daha küçük ise; hastaya medikal ekspulsif tedavi verilerek taşın spontan düşürülmesinin beklenebileceği, semptomatik olanlarda ise erkenden üreteroskopi yapılabileceği belirtilmektedir (6). Bu nedenle renal kolikten sonraki planlamada hastanın şartlarına göre karar vermek uygun olacaktır. Definitif tedavi uygulanmadan beklenecek hastaların ağrısını tedavi etmek için kullanılabilecek ilaç ve yöntemler şu şekilde özetlenebilir.

\section{a) Non-Steroid Anti Inflamatuarlar}

Renal kolik tedavisinde ilk sırada önerilen ilaçlar nonsteroid anti inflamatuarlardır (10). EAU kılavuzunun önerdiği üç ilaç diklofenak, indometasin veya ibuprofen'dir (6). Diklofenak için renal fonksiyonlarda kötüleşme yapabileceği belirtilmekle birlikte; renal fonksiyonu normal olan kişilerde bunun geri dönüşümlü olduğu bilinmektedir (11). Bu ilaçlar dışında neredeyse tüm non-steroid antiinflamatuar ilaçların (NSAI) renal kolik tedavisinde kullanılabileceği çalışmalarla gösterilmiştir. Bunlar arasında piroksikam, lornoksikam, tenoksikam, deksketoprofen sayılabilir. Piroksikam dilaltı formunun intramuskuler kadar hızlı olduğu ve lornoksikamın diğerlerinden daha hızlı etkili olduğu bilinmektedir $(12,13)$.

\section{b) Opioidler}

Opioidler renal kolik tedavisinde ilk basamakta önerilmezler. Pethidin (meperidin) dışındaki opioidlerden hid- 
romorfin, pentazosin ve tramadol ikinci basamak tedavide NSAİ'ın yetersiz olduğu durumlarda önerilirler (6). İlaç gereksinimi ve kusma başta olmak üzere ilaç yan etkilerinin (özellikle pethidin kullanımında) ağrılı dönem boyunca daha fazla olduğu bildirilmiştir $(14,15)$. Hastalara yapılan morfinin içerisine $1.5 \mathrm{mg} / \mathrm{kg}$ dozda lidokain konulmasının ağrıyı daha etkin azalttığı ve bulantıyı daha etkin önlediği görülmüştür (16). Böbrek yetersizliği olan hastalarda doza dikkat edilmelidir; çünkü nefrotoksik olmamalarına rağmen; böbrek yetersizliği olan hastalarda daha fazla birikip, solunum depresyonu ve konvulsiyon gibi yan etkilerin daha sik görülmesine neden olabilirler. Bu nedenle hastaların glomerüler filtrasyon hızına göre doz ayarlaması yapılması gerekmektedir $(17,18)$.

EAU kılavuzuna göre önerilen ilaçlar sadece NSAİ ve opioidlerdir. Bu kılavuza göre renal kolikle başvuran hastaya yaklaşım şekil-1'de gösterilmiştir. Bunların dışında kalan ve renal kolik tedavisinde etkin olduğu çalışmalarda gösterilen ilaç ve yöntemler aşağıdaki gibidir.

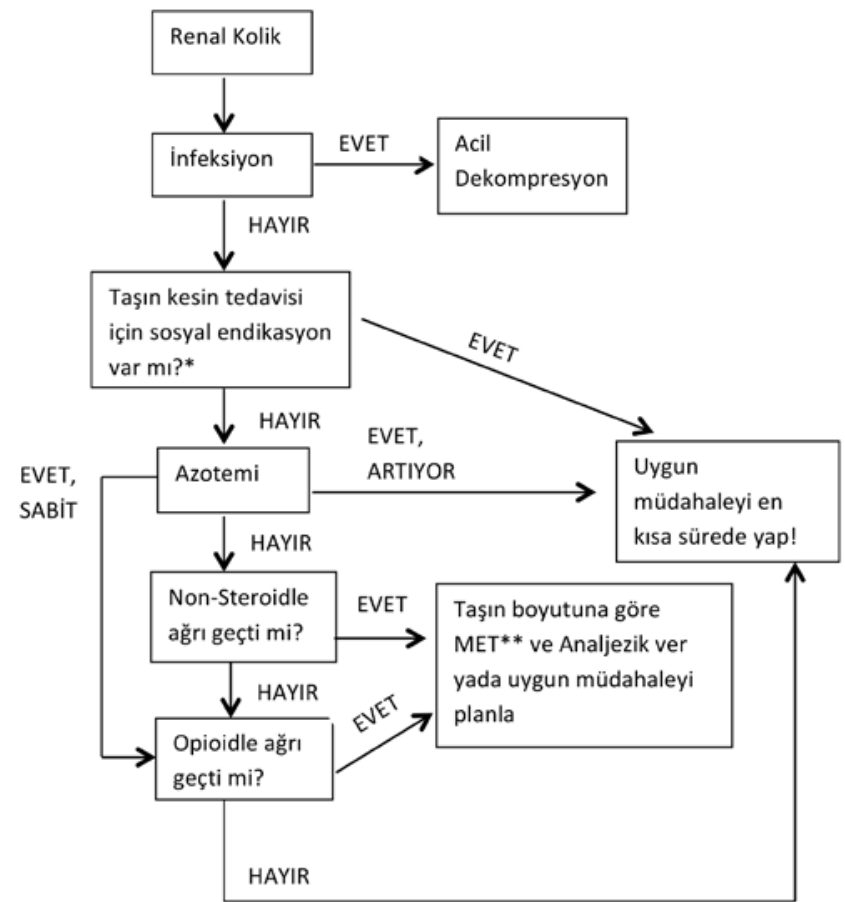

Şekil 1: EAU k1lavuzuna göre renal kolikle başvuran bir hastada tedavi algoritması. ( ${ }^{*}$ :Sosyal endikasyonlar; hastanın yaptığı iş, sağlık merkezine ulaşabilme durumu ve ağrıya olan toleransıdır. ${ }^{* *}$ MET: Medikal ekspulsif tedavi.)

\section{c) Diğer Analjezikler}

Metamizol ve parasetamol renal kolik tedavisinde EAU kılavuzunda önerilmese de yapılan çalışmalarda etkin oldukları ve güvenirliklerinin NSAI'́a göre daha fazla oldukları bildirilmiştir (19). Hatta parasetamolün piroksikam'a göre ağrıyı daha etkin azalttığını bildiren çalışma bile bulunmasına karşı; bu farkın 45 dakika sonra belirgin hale geldiği bildirilmiştir (20). Metamizol ve parasetamol özellikle renal fonksiyonları kritik olan hastalarda düşünülmelidir.

\section{d) Alfa-blokerler ve kalsiyum kanal blokerleri}

Üreterde olan $10 \mathrm{~mm}$ 'den küçük taşların ekspulsiyonu için kullanılan alfa bloker ve kalsiyum kanal blokeri'nin, taşın düşüşüne olan katkısının yanı sıra, üreter peristaltiz- mini azaltarak analjezik gereksinimini de azalttığı bilinmektedir (21). Yapılan çalışmalarda benign prostat hiperplazi (BPH)'si semptomlarının tedavisinde kullanılan tüm alfablokerlerin (tamsulosin, doksazosin, terazosin, alfuzosin, naftodipil ve silodosin) benzer etkinlikte olduğu görülmüştür (22-25). Ayrica alfabloker ile birlikte steroid verilmesinin etkinliği artırdığına dair kanıtlar bulunmakla birlikte, kanıt düzeyi düşük olduğu için rutin olarak önerilmemektedir (21). Kalsiyum kanal blokerleri'nden şimdiye kadar sadece nifedipin ile ilgili çalışmalar mevcuttur (6). Etkisinin tamsulosin'den daha az olması nedeniyle rutin kullanımı nadirdir (26).

\section{e) Spazmolitik}

Spazmolitikler, üreter düz kasında oluşan hiperperistaltizmi engelleyerek ağrının giderilmesini amaçlamaktadırlar. Ketorolak ile birlikte hiyosin n-butilbromür verilmesinin birinci saatte tek başına ketorolak verilmesine göre ağrıyı daha belirgin olarak azalttığı görülmüştür (27). Ancak n-butil bromidin taşın düşme süresini uzattığına dair veriler kullanıminı kisitlamaktadır (28).

\section{f) PDE-5 Inhibitörleri}

Üreter düz kasında fosfodiesteraz (PDE) enziminde 5 nolu tipin baskın olması görülmesi üzerine PDE-5 inhibitörünün üreter taşında kullanılması düşünülmüştür. Vardenafil, sildenafil ve tadalafil ile yapılan in vitro çalışmalarda üreter düz kasında c-GMP düzeyini artırdıkları ve gevşemeye neden oldukları gösterilmiştir. Yazarlar bu ilaçların üreteral kolik tedavisinde kullanabileceğini iddia etmişlerdir (29). Ancak henüz klinik bir çalışma yayınlanmamıştır.

\section{g) Desmopressin}

Desmopressin antidiüretik hormon (ADH) analoğu olup, glomerüler filtrasyonu azaltıcı etkisi vardır. Üriner sistem taş hastalğı'nda idrar miktarının azaltılması yoluyla, renal koliğin önlenmesi amaçlanmaktadır. Sublinguinal 120 mcg desmopressin verilen hastalarda ağrının sadece ketorolak verilenlere göre daha etkili olarak azaldığ 1 görülmüştür. Desmopressin $60 \mathrm{mcg}$ ve ketorolak kombinasyonu verilenlerde de; additif etki görüldüğü ve ağrının tek başına verilen ilaçlara göre daha fazla azaldığı görülmüştür (30). Desmopressin'in morfinle kombine edildiği bir çalışmada ise; tek başına morfine göre anlamlı bir fark sağlamadığı görülmüştür (31).

\section{h) Fitoterapi}

Üreter taşı için kullanılan en bilinen ilaç Rowatinex®'tir. Rowatinex ${ }^{\circledR}$ ile ilgili çalışmalar, in vitro olarak üreter düz kası üzerine olan gevşetici etkisinin, alfabloker ve kalsiyum kanal blokerlerinden daha fazla olduğunu göstermiştir (32). Ancak analjezik etkisi klinik çalışmalarda net değildir. Ekstrakorporeal şok dalga litotripsi tedavisi sırasında başarıyı artırdığına dair kanıtlar vardır (33).

\section{i) Hidrasyon}

Akut dönemde hastalara sıvı yüklenmesinin, ağrının giderilmesine belirgin bir katkısı olmasa da; taş pasajına minimal bir katkısı olduğu görülmüştür (34). Aynı şekilde uzun dönemde de; bol sıvı alımının veya diüretik kullanımının, ağrı veya taşın spontan deşarjına belirgin bir katkısı olduğu ispatlanamamıştır. Ancak yine de; taş pasajına mini- 
mal bir katkısı olabileceği ve hastalara önerilmesi gerektiği belirtilmiştir (35). Hastayı hidrate etmenin belirgin bir faydası olmamasının yanısıra spontan pelvik rüptüre neden olabileceği unutulmamalıdır (36). O yüzden hastaya, bol sıvı alma önerisi, mutlaka tarif edilmelidir.

j) Lokal Anestezi

Viseral ağrının, flank bölgede hissedilmesi bu bölgeye lokal anestezik uygulamasını gündeme getirmiştir. Bu mantıkla yapılan bir çalışmada, sırt bölgesinde L2-L4 vertebraların spinal prosesi'nin $1 \mathrm{~cm}$ laterali, iliak krestin $1 \mathrm{~cm}$ süperio-mediali ve 12 . kostanin ucunun $1 \mathrm{~cm}$ inferior mediali bu amaçla kullanılabilecek alanlar olarak tarif edilmiştir. Lokal anestezi uygulanmadan önce, hastanın en çok ağrısının olduğu yer tespit edilir. Önce cilt altı, ardından 4-5 cm derine, 5-10 ml \%1 lidokain enjekte edilir. Bu yöntemin uygulandığ 30 hastadan 29'unda ek bir analjezik gereksinimi olmadığ bildirilmiştir (37). Yazarlar bilinen tüm analjeziklere üstün olduğunu belirtse de; kontrol grubu olarak butilskopolamin bromid'in kullanılması çalışmanın değerini zayıflatmaktadır.

\section{k) Transkutanöz Elektriksel Sinir Stimulasyonu}

Acil servise renal kolikle başvuran hastaların bir kısmına gerçek transkutanöz elektriksel sinir stimülasyonu (TENS), bir kısmına şâm uygulaması yapılmış. Sonuçta gerçek uygulama yapılanlarda ağrı, anksiyete, bulantı skoru ve kalp hızında belirgin azalma saptanmış. Yazarlar etkinin çok çabuk başladığını ve TENS'in önemli bir ilaç dışı alternatif olabileceğini öne sürmüşlerdir (38).

\section{I) Akupunktur}

Renal kolikle başvuran hastalara parasetamol veya diklofenak verilmesiyle akupunktur yapılmasının karşılaştırıldığı bir çalışmada, vizüel ağrı skala (VAS) skorunun ilk 10 dakikada tüm gruplarda belirgin azaldığı; en belirgin azalmanın ise akupunktur yapılan grupta olduğu bildirilmiştir. Ancak ilerleyen dakikalarda analjezik yapılan hastalarda VAS skorunun akupunktur yapılanlara göre daha anlamlı düştüğü görülmüştür.

Yine de; yazarlar akupunktur'un renal kolik tedavisine yeri olabileceğini bildirmişlerdir (39).

\section{Sonuç}

Renal kolik bilinen en şiddetli ağrılardan biridir. Hastayla ilk karşılaşıldığında Şekil 1'de belirtildiği gibi acil müdahale gereksinimi mutlaka araştırılmalıdır. Eğer acil müdahale gereksinimi yoksa, taşın büyüklügüu, yeri ve hastaya ait şartlar (yaptığı iş, sağlık merkezine ulaşabilme durumu, ağrıya tolerans) göz önüne alınarak tedavinin şekli ve zamanına karar verilmelidir. Acil definitif tedavi yapılmayacak hastalara renal yetmezlik yoksa NSAI ile, renal yetmezlik varsa opioid ile analjezik tedavi uygulanmalıdır. Sonrasında taşın spontan düşmesi beklenecekse medikal ekspulsif tedavi (alfabloker) ile birlikte analjezik reçete edilmelidir. Hasta gebe ise veya NSAİ veya opioidlerin kullanımımda kontrendikasyon varsa, hastaya alternatif olarak parasetamol verilebilir. Hidrasyonun ağrıya ve taşın pasajına çok belirgin bir katkısı olmasa da önerilmelidir. Hastaya alacağı sıvıyı hangi sıklıkta ve ne kadar alacağı mutlaka tarif edilmelidir. Akupunktur gibi ilaç dışı yöntemlerin etkinliği konusu elde yeterince iyi çalışma bulunmaması nedeniyle tartışmalıdır. Ancak özellikle yaygın ilaç alerjisi olan veya ilaç kullanmaya çekinen hastalara deneyimli merkezler tarafından önerilebilir.

\section{Kaynaklar}

1. Keskinbora K. Ağrının patofizyolojisinden kronik pelvik ağrıya geçiş. Kronik pelvik ağrı (multidisipliner yaklaşım), Oral E ve Usta T. İstanbul, Güneş Tıp kitabevi, 2016; $1-5$.

2. Travaqlini F, Bartotelli T, Gacci M, Rizzo M. Pathophysiology of reno-ureteral colic. Urol Int 2004; 72 suppl 1:20-23.

3. Shokeir AA. Renal colic: new concepts related to pathophysiology, diagnosis and treatment. Curr Opin Urol 2002; 12; 263-269.

4. Shokeir AA. Renal colic: pathophysiology and management, diagnosis and management. Eur Urol 2001; 39: 241-249.

5. Song Y, Hernandez N, Gee MS, et al. Can ureteral stones cause pain without causing hydronephrosis? World J Urol. 2016; 34: 1285-8

6. C. Türk, T. Knoll, A. Petrik et al. European Urology Guidelines On Urolithiasis 2015. Available at: http:// uroweb.org/wp-content/uploads/EAU-GuidelinesUrolithiasis-2015-v2.pdf

7. Phillips E, Kieley S, Johnson EB, et al. Emergency room management of ureteral calculi: current practices. J Endourol 2009; 23: 1021-4.

8. Sarica K, Tanriverdi O, Aydin M, et al. Emergency ureteroscopic removal of ureteral calculi after first colic attack: is there any advantage? Urology 2011;78: 516-20.

9. Zargar-Shoshtari K, Anderson W, Rice M. Role of emergency ureteroscopy in the management of ureteric stones: analysis of 394 cases. BJU Int. 2015; 115: 946-50.

10. Engeler DS, Schmid S, Schmid HP. The ideal analgesic treatment for acute renal colic--theory and practice. Scand J Urol Nephrol 2008; 42: 137-42.

11. Hammad FT, Lubbad L. The effect of diclofenac sodium on renal function in reversible unilateral ureteric obstruction. Urol Res. 2011; 39: 351-6.

12. Altay B, Horasanli K, Sarica K, et al. Double-blind, placebo-controlled, randomized clinical trial of sublingual or intramuscular piroxicam in the treatment of renal colic. A comparative study. Urol Int. 2007; 79: 73-5.

13. Cevik E, Cinar O, Salman N,et al. Comparing the efficacy of intravenous tenoxicam, lornoxicam, and dexketoprofen trometamol for the treatment of renal colic. Am J Emerg Med 2012 ; 30:1486-90.

14. Holdgate A, Pollock T. Nonsteroidal anti-inflammatory drugs (NSAIDs) versus opioids for acute renal colic. Cochrane Database Syst Rev 2005 Apr;(2):CD004137.

15. Ebell MH. NSAIDs vs. opiates for pain in acute renal colic. Am Fam Physician 2004; 70: 1682.

16. Firouzian A, Alipour A, Rashidian Dezfouli H, et al. Does lidocaine as an adjuvant to morphine improve pain relief in patients presenting to the ED with acute renal colic? A double-blind, randomized controlled trial. Am J Emerg Med 2016; 34: 443-448.

17. Murtagh FEM, Chai MO, Donohoe P, et al. The use of opioid analgesia in end-stage renal disease patients managed without dialysis: recommendations for practice. J Pain Palliative Care Pharmacother 2007; 21 :5-16. 
18. Lee CR, McTavish D, Sorkin EM. Tramadol: a preliminary review of its pharmacodynamic and pharmacokinetic properties, and therapeutic potential in acute and chronic pain states. Drugs 1993; 46: 313-340.

19. Zukowski M, Kotfis K. Safety of metamizole and paracetamol for acute pain treatment. Anestezjol Intens Ter 2009; 41: 170-5.

20. Grissa MH, Claessens YE, Bouida W, et al. Paracetamol vs piroxicam to relieve pain in renal colic. Results of a randomized controlled trial. Am J Emerg Med 2011; 29: 203-6.

21. Seitz C, Liatsikos E, Porpiglia F, et al. Medical Therapy to Facilitate the Passage of Stones: What Is the Evidence? Eur Urol 2009; 56: 455-71.

22. Yilmaz E, Batislam E, Basar MM, et al. The comparison and efficacy of 3 different alpha1-adrenergic blockers for distal ureteral stones. J Urol 2005; 173: 2010-2.

23. Agrawal M, Gupta M, Gupta A, et al. Prospective Randomized Trial Comparing Efficacy of Alfuzosin and Tamsulosin in Management of Lower Ureteral Stones. Urology 2009; 73:706-9.

24. Sun X, He L, Ge W, et al. Efficacy of selective alpha1DBlocker Naftopidil as medical expulsive therapy for distal ureteral stones. J Urol 2009; 181: 1716-20.

25. Gupta S, Lodh B, Singh AK, et al. Comparing the efficacy of tamsulosin and silodosin in the medical expulsion therapy for ureteral calculi. J Clin Diagn Res 2013; 7(8): 1672-4.

26. Porpiglia F, Ghignone G, Fiori C, et al. Nifedipine versus tamsulosin for the management of lower ureteral stones. J Urol 2004; 172: 568-71.

27. Yakoot M, Salem A, Yousef S, et al. Clinical efficacy of Spasmofen ${ }^{\circledR}$ suppository in the emergency treatment of renal colic: a randomized, double-blind, double-dummy comparative trial. Drug Des Devel Ther 2014; 8: 405-10.

28. Gurbuz MC, Polat H, Canat L, et al. Efficacy of three different alpha 1-adrenergic blockers and hyoscine N-butylbromide for distal ureteral stones. Int Braz J Urol 2011; 37: 195-200.

29. Gratzke C, Uckert S, Reich O, et al. PDE5 inhibitors. A new option in the treatment of ureteral colic? Urologe A 2007; 46: 1219-23.
30. Pricop C, Branisteanu DD, Orsolya M, et al. Sublingual desmopressin is efficient and safe in the therapy of lithiasic renal colic. Int Urol Nephrol 2016; 48: 183-189.

31. Keshvari Shirvani M, Darabi Mahboub M, Ghazi M, et al. A comparison of the effects of morphine and sublingual desmopressin combination therapy with morphine alone in treatment of renal colic: a controlled clinical trial. Urol J 2015; 12: 2001-4.

32. Whan Lee J, Young Lee M, Young Seo I. In-vitro study on ureteral smooth muscle contractility with tamsulosin, nifedipine, and terpene mixture (Rowatinex ${ }^{\circledR}$ ). Minerva Urol Nefrol 2015 Jun; 67:91-6.

33. Kim DH, Goh HJ, Lee HW. The effect of terpene combination on ureter calculus expulsion after extracorporeal shock wave lithotripsy. Korean J Urol 2014; 55:36-40.

34. Springhart WP, Marguet CG, Sur RL, et al. Forced versus minimal intravenous hydration in the management of acute renal colic: a randomized trial. J Endourol. 2006; 20: 713-6.

35. Worster AS, Bhanich Supapol W. Fluids and diuretics for acute ureteric colic. Cochrane Database Syst Rev. 2012 Feb 15;2:CD004926.

36. Hess B. Medical management of acute renal colic - there is more than hydration and Buscopan. Praxis (Bern 1994). 2011; 100: 293-7.

37. Iguchi M, Katoh $\mathrm{Y}$, Koike $\mathrm{H}$, et al. Randomized trial of trigger point injection for renal colic. Int J Urol 2002; 9: 475-9.

38. Mora B, Giorni E, Dobrovits M, et al. Transcutaneous electrical nerve stimulation: an effective treatment for pain caused by renal colic in emergency care. J Urol. 2006; 175(5): 1737-41.

39. Kaynar M, Koyuncu F, Buldu I, et al. Comparison of the efficacy of diclofenac, acupuncture, and acetaminophen in the treatment of renal colic. Am J Emerg Med 2015; 33: 749-53.

Yazışma Adresi:

Orhan Tanriverdi,

Bahçeşehir Üniversitesi, Tıp Fakültesi, Üroloji Ana Bilim Dalı, Liv

Hospital, İstanbul

Tel: +90 5323244393

e-mail: otanriverdi@gmail.com 